\title{
El bípedo implume dependiente
}

\section{The dependent featherless biped}

\author{
Eugenio Matijasevic, Bogotá D.C.
}

Las palabras son herramientas con las que los seres humanos desencadenamos eventos en el mundo humano (1). Cuando mediante una palabra un hablante menciona un particular, bien sea concreto o abstracto, ocurren dos fenómenos simultáneos en la mente de nosotros, sus oyentes: en primer lugar, "comprendemos" el significado de la palabra en cuestión incluyéndola en un conjunto de conceptos que "funcionan" en una misma región del mundo humano delimitando de manera precisa el particular al que se refiere; y, en segundo lugar, "sentimos" la palabra en cuestión, es decir, nos embarga una emoción o una mezcla de emociones, que pueden asociarse en mayor o menor medida con imágenes muy cargadas afectivamente (de gestas personales o ajenas, de sucesos del mundo en los que hemos tomado parte o en los que otros han tomado parte, de eventos de nuestro mundo interior en los que ciertos recuerdos, deseos, emociones y deliberaciones nuestras han desempeñado un cierto papel).

Pongamos como ejemplo la mención de la palabra justicia en el transcurso de un diálogo casual. En primer lugar, "comprendemos" su significado atrapando la palabra en cuestión en una red de conceptos que de una u otra manera delimitan su alcance (a quiénes o a qué se puede aplicar la palabra) y establecen su uso (en qué circunstancias el empleo de la palabra justicia resulta correcto). Propongo, tentativamente, como red conceptual para el término justicia, los conceptos: igualdad, equidad, representatividad, distribución, no discriminación, fraternidad. En segundo lugar "sentimos" la palabra justicia en el conjunto de emociones, a veces contradictorias, que nos sobrevienen al escucharla. Propongo tentativamente como tono emocional (por darle algún nombre a ésta fenómeno) del término justicia, sentimientos como: alegría, satisfacción, interés, esperanza. El aspecto emocional o no conceptual, como se mencionó, incluye siempre una cierta imaginería que refuerza o atenúa, añade o contrapone emociones al término justicia; yo personalmente, por razones (motivos) que yo y sólo yo conozco, cuando oigo hablar de justicia pienso en la vida de Martín Luther King, en algunos pasajes de Don Quijote de la Mancha y en una obra de Bertolt Brecht que remite a Salomón.

Pero también puede ocurrir que a la mención del término justicia nuestra intelección de su significado ocurra en otra dirección, con otro sentido de justicia (autoridad, tribunal, condena, prisión, ajuste de cuentas, etc.) y que, en tal caso, las emociones que nos embarguen sean otras (temor, odio, culpa, vergüienza), acompañadas de imágenes muy cargadas emotivamente (como, para no establecer asociaciones clandestinas con la situación contemporánea, el baño de sangre generado por el Comité de Salut Public durante el reinado del terror del directorio en plena revolución francesa o, más cerca de nosotros en el tiempo y en el corazón, la dictadura Argentina de la década de 1970).

Esta breve disquisición sobre la justicia no es más que un ejemplo de cómo cada palabra posee un significado conceptual y un tono emocional (o, si se prefiere, un significado emocional y un tono conceptual); ustedes mismos podrían aportar sus propios ejemplos, seguramente son tan numerosos como las palabras cuyo significado comprenden o como las palabras que saben usar [hay quienes consideran que comprender una palabra y saberla usar son lo mismo (2)].

Resumiendo, una vez dicha una palabra (o un conjunto de palabras), quien la emite desencadena en sus oyentes una serie de eventos físicoquímicos (fisiológicos) y mentales (cognitivos y emocionales) que, finalmente, llevan al despliegue de una red específica de conceptos (su significado conceptual) y una red de emociones (su tono emocional), que
Dr. Eugenio Matijasevic: Editor General Acta Médica Colombiana. Bogotá, D.C. (Colombia)

E-mail: eugenio.matijasevic@gmail.com Recibido: 01/VII/2014 Aceptado: 01/VII/2014 
ponen en marcha en la mente y en el cuerpo del oyente pensamientos, deliberaciones, decisiones y acciones capaces de modificar el mundo.

Con frecuencia, sin embargo, tanto hablantes como oyentes conseguimos separar el significado conceptual de una palabra del tono emocional que la acompaña. Para Freud, que no fue el primero ni el último en describir este fenómeno, en tales casos "[...] queda separado el afecto de su idea, después de lo cual sigue cada uno de estos elementos su destino particular [...] (3)".

Es por ello que en ocasiones hablamos de violencia y de crímenes de guerra y de desapariciones forzadas y de refugiados y de desplazados internos sin que un escalofrío recorra nuestras nervaduras; o hablamos de inundaciones, huracanes y terremotos sin que alcancemos siquiera a rozar el temblor y el hambre y el frío y la pavura de esos seres humanos que, a diferencia de nosotros, no están narrando o describiendo sucesos vividos por otros sino sufriéndolos en carne propia. También solemos hablar de dolor y disnea y temor y angustia y, en general, de todas las formas de sufrimiento, somático y psíquico, que se abaten sobre nuestros pacientes, sin arribar siquiera a un atisbo de lo que eso significa en la carne y en el alma para las personas a las que hemos ayudado a encontrar diagnósticos como cáncer o evento coronario o asma o neuropatía o enfermedad vascular periférica. Es como si construyésemos artificiosa y trabajadamente en nuestra mente el significado conceptual y corporal-emocional de cada palabra pero, también con mucho trabajo y artificio, lográramos eliminar siempre este último.

Esta disociación entre el aspecto conceptual y el aspecto emocional del significado de una palabra es mucho mayor para unos términos que para otros y varía también dependiendo de cada persona, de su experiencia previa, de su historia emocional previa y del uso previo que haya hecho, con otras personas, de una determinada palabra-herramienta.

En ocasiones, además, el proceso de disociación va mucho más allá, y de la misma manera que separamos, en las palabras que compartimos con otros seres humanos, los significados conceptual y emocional anulando este último, llegamos al extremo de disociar también la relación completa que establecemos con los demás (con la ayuda de esas mismas palabras) y bloqueamos, ya no sólo en las palabras que compartimos sino en la relación misma, la intervención de la más mínima emoción humanizadora.

Probablemente este desprecio por lo emocional provenga de una exageración, hasta la perversión, de la idea aristotélica de que es la razón, el $\lambda$ ó $\gamma$ os (logos), lo que nos hace humanos.

La verdad es que desde antiguo hemos estado interesados por saber qué es lo que nos hace humanos, lo que nos identifica con respecto a otras especies animales que pueblan el mundo. La anécdota, aunque en realidad parece un chiste, transmitida por Diógenes Laercio en su libro Vidas, opiniones y sentencias de los filósofos más ilustres, cuenta que Platón, tratando de definir a los seres humanos por el mínimo de características que los acogiera a todos bajo la misma definición, había afirmado que el ser humano era un animal bípedo sin plumas.

Obviamente Platón no afirmó semejante exabrupto, pero en uno de sus diálogos socráticos, El Político, tratando de

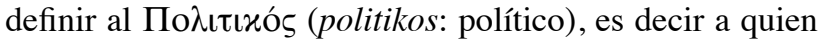

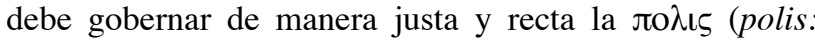
ciudad-estado), encuentra que éste se diferencia de manera tajante del sofista y se identifica plenamente con el filósofo; pero en el proceso dialéctico de llegar a esa diferenciación y a esa identificación, el argumento pasa por la idea de que un buen gobernante debe ser algo así como un buen criador de animales, una especie de pastor de hombres, pastor del rebaño humano (4). Aunque finalmente abandonará esta analogía, la argumentación se pierde por un tiempo en los meandros inútiles de tratar de definir al ser humano para ver si, en realidad, el criador de animales se parece al gobernante de este caso especial de animales, los seres humanos. El argumento avanza como un algoritmo dicotómico en el que, cada vez que se elige una de dos ramas posibles, la elegida, a su vez, da origen a otras dos: de la crianza de animales surge la dicotomía entre la crianza de animales salvajes y la de animales domésticos o mansos (grupo, este último, que incluye al hombre), entre los domésticos la crianza de los que viven en el agua es diferente de la de los animales que viven en tierra seca (grupo, este último, que incluye al hombre), entre los que viven en tierra seca la crianza de los volátiles es diferente de la de los animales pedestres (grupo, este último, que incluye al hombre), entre los pedestres la crianza de los que tienen cuernos es diferente de la de los animales sin cuernos (grupo, este último, que incluye al hombre), entre los sin cuernos la crianza de los animales que admiten cruces entre especies (asnos y caballos, por ejemplo) es diferente de la de los que no admiten cruces (grupo, este último, que incluye al hombre), entre los que no admiten cruces la crianza de los animales que tienen cuatro extremidades inferiores es diferente de la de los que tienen dos (grupo, este último, que incluye al hombre), y entre estos últimos la crianza de los animales que tienen plumas es diferente de la de los que no las tienen (grupo, este último, que incluye al hombre, de donde la idea de que el hombre es un bípedo implume, aunque en realidad habría que decir con Platón que el hombre es un animal doméstico, terrestre, pedestre, sin cuernos, que no admite cruces, bípedo y sin plumas) (5).

Diógenes de Sinope, el cínico (continúa la anécdota o el chiste recogido por Diógenes Laercio), se presentó un cierto día al salón de conferencias de la Academia de Platón con un pollo desplumado diciéndoles: "aquí está el hombre de Platón". El chiste termina afirmando que, para evitar ese tipo de confusiones (pues, de acuerdo con la definición de Platón tanto el hombre como el pollo de Diógenes eran "bípedos implumes") en adelante la definición de hombre se había modificado a "bípedo implume con uñas planas", definición 
que, sin lugar a dudas, excluye al pollo del filósofo cínico y sólo se puede aplicar al hombre (6).

Mucho se ha discutido sobre la arbitrariedad de los criterios seleccionados por Platón para hacer esta especie de taxonomía de la especie humana (7), pero no hay que olvidar que no es realmente una taxonomía sino un intento un poco absurdo de analogía entre los criadores de animales y los "pastores de hombres", y que tampoco es una definición acabada de nuestra especie. El problema con Platón en esto de las definiciones es que apenas se estaba desarrollando en la historia del pensamiento occidental un método capaz de definiciones adecuadas y que no era Platón sino Aristóteles quien lo estaba logrando. Habrá que esperar la obras de lógica de Aristóteles, en especial Analytica posteriora, y su Metafísica para tener herramientas conceptuales y lógicas capaces de darnos definiciones y taxonomías menos arbitrarias. Mediante las herramientas adecuadas, Aristóteles evita cometer el tipo de errores que le permitieron a Diógenes mofarse de Platón y llega a definiciones muy precisas mediante estrategias que nos enseñó también a nosotros. La insistencia de Aristóteles en el logos como aspecto diferenciador del hombre con respecto a otros animales hace parte de estas estrategias.

El término logos, que hemos dado en traducir al castellano como razón desde la perspectiva filosófica y como verbo o palabra desde la perspectiva bíblica ["En el principio existía la Palabra y la Palabra estaba con Dios, y la Palabra era Dios" (8), "En el principio era el Verbo, y el Verbo era con Dios, y el Verbo era Dios" (9)] podría haberse traducido también por expresión oral, declaración, lenguaje, discurso, conversación, charla, discusión, proposición, definición, promesa, pretexto, fama, nombradía, ejemplo, fábula, historia, narración, revelación divina, rumor que corre, relación, proporción, medida, razón de ser, causa, explicación, justificación, argumento, prejuicio y otras tantas más, pues todos estos sentidos tenía en el uso cotidiano el término $\lambda$ ó $\gamma$ os en

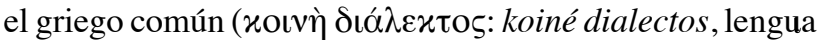
común) que hablaban en el día a día los contemporáneos de Aristóteles (10). Obviamente, las traducciones filosófica y bíblica mencionadas han sido realizadas tratando de mantener el contexto, buscando conservar el sentido original del término, pues no habríamos quedado muy bien los seres humanos si hubiéramos puesto a decir a Aristóteles que el hombre es un animal fabulador o un animal con prejuicios (aunque en ciertas circunstancias nos habríamos aproximado más a la verdad) y seguramente la buena nueva de Juan (escrita originalmente en koiné dialectos) no hubiese tenido un comienzo tan poético si dijese "En el comienzo existía la proporción".

De todas maneras, cuando en castellano hablamos de razón, cuando al traducirlo hacemos decir a Aristóteles que "el hombre es un animal racional" (frase que, como veremos, en realidad nunca dijo), no alcanzamos a captar los sentidos que al término logos le quiso dar Aristóteles. Obviamente, Aristóteles tomó el término del lenguaje cotidiano, pero des- de el punto de vista técnico le dio tres sentidos muy precisos. Uno en su retórica, otro en su psicología y otro en su ética.

Desde el punto de vista de la retórica aristotélica, la capacidad de encontrar los medios para persuadir mediante la palabra ["la función de la retórica-afirma Aristóteles- no es persuadir, sino encontrar en cada caso los medios existentes de persuasión" (11)] depende de un adecuado dominio de los tres aspectos fundamentales de la comunicación con

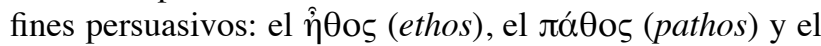
logos. El ethos es un medio de persuasión que concierne a la capacidad del orador para evocar en la audiencia un carácter personal con atributos positivos: si ésta llega a considerar que el orador es competente, conoce el asunto a tratar, es sensato, tiene buenas intenciones y no está sesgado desde el punto de vista moral (no tiene conflicto de intereses, diríamos en la actualidad), estará mucho más inclinada a creer en lo que el orador le diga. El pathos es el medio que tiene que ver con las emociones, acompañadas de placer o de dolor, que el orador sea capaz de suscitar en la audiencia, modificando mediante ellas la disposición de ánimo y, consecuentemente, las opiniones que sus oyentes se forman antes de emitir un juicio (12). El logos hace referencia en este caso al medio de persuasión que apela al intelecto mediante la argumentación capaz de demostrar la verdad de un enunciado a partir de sus premisas mediante un entimema (similar en retórica al silogismo de la lógica) o mediante un ejemplo (similar en retórica a la inducción lógica) (13).

Desde el punto de vista de su psicología, Aristóteles considera que, como todos los seres, los seres humanos estamos

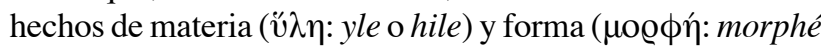
o morfé), y que, como todos los seres vivos, nuestra forma

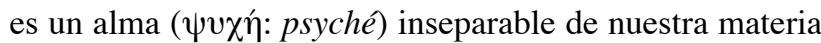
pues sólo existe (y nos hace existir) como forma o función de ésta ["Si el ojo fuera un animal -dice Aristóteles- la visión sería su alma" (14)]. Ahora bien, para Aristóteles nuestra psyché tiene diversas funciones: tiene una función vegetativa, similar a la que cumple el alma de las plantas, que nos permite nacer, nutrirnos, crecer, reproducirnos; tiene una función animal, similar a la que cumple el alma de los animales, que nos provee de movimiento y de volición (instintos, apetitos y deseos) (15); y tiene una función exclusiva del ser humano, que nos define como humanos, que es el $\log o s$, la capacidad de razonar, enjuiciar, inteligir e, incluso, inteligirse a sí mismo (16).

Desde el punto de vista ético debe recordarse que la ética

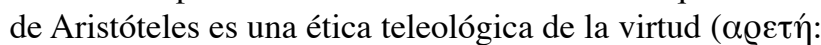

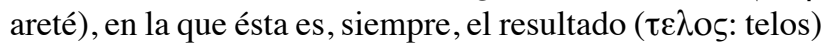
de un propósito; el desarrollo de una función ( No se trata de una ética deóntica o normativa basada en el cumplimiento de reglas preestablecidas. El mayor bien en la vida humana es, para Aristóteles, la búsqueda de la felicidad, así que es éste el propósito verdaderamente ético de todo ser humano. Pero la felicidad no se encuentra en el placer, los honores, las riquezas, los puestos de mando, la gloria, etc. sino en la areté (todos los seres humanos, sabios y no 
tan sabios, "admiten que vivir bien y obrar bien es lo mismo que ser feliz” (17) afirma Aristóteles). La virtud-areté y por tanto la felicidad derivan, para Aristóteles, del cumplimiento pleno de una función; la areté de un médico, por ejemplo, consiste en que logre la salud de sus pacientes. La función de un ser humano, el propósito de sus actividades como ser humano es, para Aristóteles, obvia: si el el logos es lo que nos hace más humanos, diferentes de las plantas y de los animales, entonces nuestra areté, nuestra virtud como seres humanos, ha de ser llevar dicho logos a su desarrollo más completo (18). Aquí retoma el concepto de logos en un sentido parecido al que utilizó en Acerca del Alma aunque con connotaciones sociales y éticas que antes no tenía, pues desde el punto de vista ético, el logos ya no es sólo la capacidad de razonar, enjuiciar, inteligir e, incluso, inteligirse a sí mismo de manera individual, aislada, sino también la capacidad de percibir, de darnos cuenta (en plural), y de aclarar a otros mediante el discurso razonado, la diferencia entre lo que trae ventajas y lo que es peligroso, lo que es justo y lo que es injusto, lo que es bueno y lo que es malo,

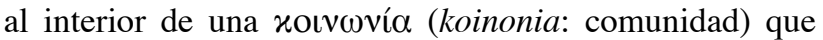
se constituye en el hogar, la ciudad-estado, la polis, único escenario en donde todo esto es posible (19).

La razón, el logos, no es pues una mera facultad escondida en el fondo de la psyché, es además una actividad ( $₫ \hat{\alpha} \xi ı \zeta$, praxis) que se despliega en la polis, en la comunidad humana, que se realiza en el intercambio con otros seres humanos, que hace de la capacidad de entender y poder explicar el motivo de nuestras acciones y de la capacidad para evaluar qué es lo mejor para nosotros mismos una virtud que debemos perseguir y alcanzar, colocando como meta más lograda y distante la capacidad de entender que lo mejor para mí mismo no puede separarse de lo mejor para todos, puesto que somos animales políticos, animales que vivimos en sociedad, animales que convivimos en la polis. Así lo declara Aristóteles de manera explícita al comienzo

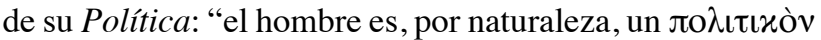

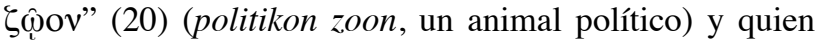
no sea parte de la ciudad, bien sea por incapacidad para integrarse a esa participación común, o bien porque en su autosuficiencia considera que no necesita de ella, no es otra

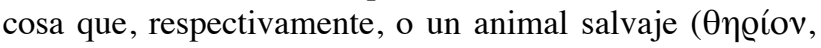
therion) o un Dios ( $\theta \varepsilon$ cós, theos) (21).

Estas dos circunstancias, el que por un lado Aristóteles, desde su perspectiva retórica, psicológica y ética, considerara que lo que nos hace humanos, lo que nos diferencia de los animales es el logos, la razón, y, por el otro, que desde su perspectiva política hubiese afirmado que "el hombre es un animal político", llevó, con el paso del tiempo, a que se le atribuyera una frase que ha pasado a ser proverbial como definición del ser humano pero que Aristóteles nunca dijo:

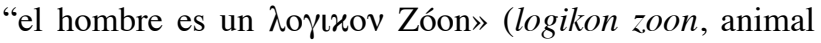
racional). De ahí a considerar que sólo debemos privilegiar el logos, la razón, en desmedro de otras facultades que también son humanas, pero que compartimos con los animales, como la emocionalidad, la instintualidad o la sensibilidad, no había sino un paso.

Seguramente lo más específico del hombre es su logos, su razón, pero esto no hace que las emociones sean inhumanas o que haya que rechazarlas en la vida de relación o que, al interior de la polis, una relación que intente basarse exclusivamente en la razón sea más humana que otra que permita que las emociones ayuden a reforzar los lazos que nos unen. Sin embargo, desde antaño venimos privilegiando la razón, privilegio que la razón merece, aunque no de manera exclusiva o, menos todavía, excluyente de las emociones y los afectos.

En su novela Diario un Mal Año, John Maxwell Coetzee, Premio Nobel de literatura del año 2003, trae a la memoria del narrador y personaje principal el recuerdo de un episodio que tuvo lugar, supuestamente, en la biblioteca de la Universidad Johns Hopkins de Baltimore mientras hacía algunas consultas bibliográficas. "A cada una de mis preguntas", dice el narrador, la bibliotecaria "respondía de una manera rápida y monótona, dejándome con la inquietante sensación de que no estaba hablando con un congénere sino con una máquina". Además de lo molesta que podía resultar la actitud de la bibliotecaria, lo más abrumador de la situación, continúa el narrador, era que "realmente, la joven parecía enorgullecerse de su identidad mecánica, de su insociabilidad". La actitud maquinal de la bibliotecaria no sólo se declaraba en el hecho de mostrarse como una máquina dirigida por un programa inflexible, sino en negar al otro cualquier posibilidad de interacción, cualquier posibilidad de una mínima modificación en su algoritmo: "No buscaba nada de mí en el intercambio -culmina Coetzee-, no había nada que yo pudiera darle, ni siquiera el tranquilizador instante de reconocimiento mutuo que comparten dos hormigas cuando sus antenas se rozan al pasar" (22).

Aunque se trata de una situación novelada, los eventos descritos por Coetzee no son infrecuentes en la vida real; con seguridad cada uno de nosotros puede recordar un episodio reciente en el que alguien, en el transcurso de una interacción humana, trató de desaparecer de la mirada del otro como ser humano trabajando activamente por parecer un autómata o un robot, un artefacto programado para realizar un oficio humano sin parecer humano. En los últimos tiempos y en muchas de las profesiones u oficios en los que, como parte del oficio, quien lo realiza debe interactuar con otro ser humano, da la impresión de que la consigna fuese "no involucrarse"; algo así como si cada quien dijese "mi trabajo es un trabajo muy importante y mientras menos emociones permita que se inmiscuyan en él, mejor lo haré", olvidando que, precisamente, la importancia de su trabajo se deriva de que es un trabajo a realizar con otros seres humanos, un trabajo que no podría ser sustituido por un algoritmo de computador o por el juego de engranajes de un autómata, y que, en consecuencia, se trata de un trabajo pleno emociones. A veces, en el argumento anterior, se remplaza "muy importante" en "mi trabajo es muy importante" 
por "calificado" o "técnico" o "científico", pero, en última instancia, la intención es la misma, creer y hacer creer que la presencia de emociones humanas en un intercambio humano entorpecen dicho intercambio y justificar la total disociación entre el contenido conceptual de lo que decimos y el tono emocional que debería acompañarlo con el fin de erradicar por completo el clima emocional en el que debería darse toda interacción humana.

En 1974 Herbert Freudemberger, psicólogo dedicado a estudiar los efectos del trabajo sobre la salud física y emocional, describió una forma especial de desgaste laboral, que se presenta sólo entre trabajadores pertenecientes a sectores en los que el trabajo está dirigido hacia otros seres humanos (trabajadores de la salud, educadores, servicios de hotelería, empleados de la justicia, servicios sociales, etc.), cuando existe un desfase entre las expectativas del trabajador y la recompensa que realmente obtiene de su trabajo (olvidando que, en gran medida, obtiene lo que da). Freudemberger denominó burnout a esta situación, término que no tiene una traducción precisa al castellano pero que en inglés se usa cuando el motor de un jet o de un cohete cesa de funcionar al quemar (burnout) todas sus reservas de combustible (23). En castellano un equivalente aproximado podría ser "fundió el motor" o "quemó la máquina", pero no vale la pena adaptar una traducción: en todos los idiomas del mundo el término burnout, así sin traducción, ha pasado a significar ese grado de agotamiento laboral que no tiene que ver con la fatiga muscular ni con el cansancio intelectual sino con la insatisfacción con la labor realizada.

Al trabajador en burnout, de acuerdo con Christina Maslach, psicóloga de la Universidad de Berkeley quien en 1976 formalizó los conceptos de Freudemberger en la primera escala de burnout con utilidad práctica y con un aceptable grado de reproducibilidad y de concordancia interobservador (24), lo que antes le parecía importante de su labor le parece ahora poco agradable, autoevaluando negativamente su propia capacidad para llevar a cabo ese trabajo; la energía de la que hacía gala en las actividades laborales da paso al cansancio, a la incapacidad de dar más de sí mismo desde el punto de vista emocional; y el compromiso que vivía hacia las personas destinatarias de su trabajo da lugar a un cinismo atroz, a tal grado que comienza a tratarlas como si fueran objetos impersonales. Es la otra cara de la moneda de la bibliotecaria de Coetzee, ya no se trata de que adoptemos una actitud automática inhumana, convirtiendo nuestro trabajo en el trabajo de una máquina y transformándonos a nosotros mismos en un objeto impersonal, sino que transformamos al otro en un evento del mundo, en un objeto impersonal, sin emociones que, a su vez, tampoco nos emociona.

En cualquiera de los dos casos desaparece la posibilidad de una relación humana, pues no es posible una relación interpersonal entre una máquina y una persona ("modelo bibliotecaria de Coetzee") ni entre una persona y un objeto del mundo ("modelo trabajador en burnout"). De todas maneras, el intento vano por erradicar las emociones de las relaciones humanas no deja de ser un mecanismo de defensa y como tal parte de un proceso patológico: para no verme afectado por los demás me niego a mí mismo y me transformo en máquina o niego la presencia de los demás declarándolos objetos en un mundo de objetos.

Desde la perspectiva del sentido común los seres humanos siempre hemos admitido que de una persona podemos predicar tanto características netamente físicas, que cualquiera puede verificar (como la talla, el peso, la situación en el espacio, la concentración de ciertos componentes bioquímicos en sus líquidos corporales), como características de su mundo interior que sólo el propio sujeto puede confirmar (y que sólo podemos conocer si él nos las comunica) que hemos dado en denominar mentales (tiene miedo, está enamorado, le preocupa la salud de su amigo) (25). Peter Frederick Strawson, el filósofo oxoniense que más hizo en pro de lo que denominó la filosofía del sentido común, dedicó parte de sus reflexiones a la forma en que los seres humanos nos relacionamos unos con otros, en especial a las posturas intelectuales, cognitivas y emocionales que asumimos frente a los demás. Strawson llamó a estas posturas "actitud frente a los demás" y demostró que dichas posturas pueden ser determinantes no sólo del curso que tome una relación humana y de los resultados del encuentro entre dos o más seres humanos sino que, a partir de ellas, se desarrollan en los grupo de seres humanos que viven, trabajan, se relacionan e interactúan de manera mancomunada lo que él considera una comunidad racional de la que, posteriormente, en un grado más avanzado de la evolución comunitaria, se desarrollará una comunidad moral.

Aunque puede haber combinaciones diversas dentro de un amplio rango de posibilidades, en última instancia, en su estado más puro, afirma Strawson, asumimos frente a los demás y los demás asumen frente a nosotros sólo dos tipos de actitudes que denominó, respectivamente, actitud objetiva y actitud reactiva. A primera vista, guiados por las connotaciones que términos como objetividad y juzgar objetivamente tienen en la conversación del día a día, a cualquiera que se le interrogue sobre cómo considera que debería relacionarse con los demás respondería de inmediato que de manera objetiva, pero, asombrosamente, Strawson nos enseña que precisamente la característica más humana de las relaciones entre los seres humanos es que nos relacionamos de manera emocional y afectiva (26).

De acuerdo con Strawson adoptamos una actitud objetiva frente a los demás cuando vemos al otro de manera "objetiva", igual que al resto de eventos que tienen lugar en el universo, como a un objeto más entre los muebles del mundo. En este caso el otro es algo de lo que podemos predicar características exclusivamente objetivables como la posición en el espacio, la talla, el peso, la carga eléctrica o las modificaciones en la misma, las características bioquímicas, etc. De todas maneras, al adoptar esta actitud tratamos de desprendernos de cualquier vínculo emocional que, supuestamente, pueda entorpecer nuestro buen juicio 
científico con respecto a ese objeto del mundo que estamos observando, olvidando o haciendo como si olvidáramos, que estamos frente a un semejante.

Por el contrario, cuando adoptamos una actitud reactiva frente a los demás, vemos al otro como una persona, como alguien que posee ciertas características físicas (como en la actitud objetiva), pero que tiene también un mundo interior como el nuestro, un mundo con percepciones, sensaciones, emociones, sufrimiento; lo vemos como un semejante, alguien que es a la vez un soma y una psyché, alguien de quien podemos predicar enunciados tanto físicos (está en tal sitio, en tal posición, mide tanto, pesa tanto) como mentales (tiene miedo, está enamorado, sufre). En este caso tratamos, incluso a veces, de ponernos en la situación del otro (hay palabras a menudo olvidadas como compasión y misericordia para describir este fenómeno pero que, con un cierto pudor o por las supuestas connotaciones religiosas que conllevan, hemos reemplazado por el término más neutro de empatía).

Alasdair MacIntyre, también filósofo oxoniese, aunque está de acuerdo con la idea aristotélica de que la razón es lo que nos hace específicos con respecto a otros animales, considera que la frase que no dijo Aristóteles pero que todos le atribuimos puede seguir siendo cierta si la mejoramos añadiéndole un criterio modificador que la matice y la haga más cierta: "El hombre es un animal racional y dependiente" (27). De acuerdo con MacIntyre, a diferencia de muchos animales que desde el momento en que salen del huevo o del vientre materno están en condiciones de enfrentarse a las vicisitudes del mundo natural, los seres humanos en muchas circunstancias de la vida, en especial en las edades extremas de la misma, dependemos de otros seres humanos, no digamos ya para florecer (dependemos siempre de los demás para dar fruto), sino para simplemente sobrevivir: somos vulnerables a una gran cantidad de aflicciones diversas -recalca MacIntyre- y la mayoría padecemos alguna enfermedad grave en uno u otro momento de la vida, pero la forma en que cada uno de nosotros se enfrenta a ello depende sólo en una pequeñísima parte de sí mismo, "pues lo más frecuente es que, cuando nos enfrentamos a una enfermedad, a una lesión corporal, a una alimentación defectuosa, a deficiencias o perturbaciones mentales o, incluso, a la agresión o a la negligencia de otros seres humanos, todos dependemos de los demás".

Donald Woods Winnicott, médico pediatra y psicoanalista de niños británico, quien trabajó durante 40 años como pediatra en el Paddington Green Children's Hospital (28) y dedicó toda su vida profesional a la observación, cuidado y tratamiento de niños tanto sanos como enfermos, dijo alguna vez en una conferencia que "no hay algo que pueda ser denominado un bebé" ("there is not such thing as a baby") y tuvo que explicarse en varias ocasiones porque esta afirmación se tomó como pudieron haberse tomado los exabruptos de Platón cuando a través de los recovecos de su dificultosa argumentación pareció afirmar que "el hombre es un animal bípedo implume". La mejor explicación de la afirmación de
Winnicott la consignó por escrito: "si me muestran ustedes un bebé, con seguridad me mostrarán también a alguien que cuida del bebé, o, por lo menos, un cochecito de bebés con los ojos y los oídos de alguien pegados a él; lo que vemos es una pareja de crianza (a nursing couple)" (29). Y tiene razón, los niños no aparecen y permanecen en el mundo sin alguien que esté al cuidado de ellos. No se crían solos, no sobrevivirían un solo día sin un cuidador que en conjunto con ellos forme una nursing couple. Los adultos en las condiciones de vulnerabilidad y dependencia descritas por MacIntyre tampoco lograríamos sobrevivir mucho tiempo si en esas situaciones no lográramos conformar con alguien una nursing couple que nos ayude a sobrevivir y salir adelante.

Desde hace casi 25 siglos, cuando en la Escuela de Cos se establecieron las bases humanas, humanistas y científicas de nuestra profesión, la medicina y las profesiones que se han ido gestando alrededor del cuidado de los enfermos y de la promoción de la salud humana, se han diferenciado, como parte del proceso de división social del trabajo, como oficios dirigidos a otros seres humanos, con la tarea de formar nursing couples con las personas enfermas o en riesgo de enfermedad, que no sobrevivirían ni podrían posteriormente florecer y fructificar por fuera del amparo protector de una "pareja de crianza" establecida con una persona idónea. Este tipo de relación tan especial, que hemos dado en llamar relación médico-paciente, es una relación humana, una relación entre seres humanos, racional pero a la vez plena de emociones. No puede permitirse que sea una relación estructurada sobre el modelo "bibliotecaria de Coetzee" entre una máquina y un paciente humano (sufriente y doliente) o una relación sobre el modelo "trabajador en burnout" entre un médico supuestamente humano (sufriente y doliente) que, para "protegerse", deshumaniza a su paciente convirtiéndolo en un objeto del mundo.

La humanización del cuidado de la salud, tarea en la que estamos involucrados todos, médicos, enfermeras, terapeutas y pacientes, requiere que siempre y en cada tiempo y lugar en el que dos personas se encuentren en esa relación tan especialmente asimétrica en la que un ser humano desvalido podría salir de su situación o sobrellevarla mejor con la ayuda de otro ser humano que conoce las teorías y las técnicas necesarias para lograrlo, tengamos el empeño, independientemente del lado de la relación en el que estemos (como pacientes o como terapeutas), de personalizar al otro, de tenerlo presente como una persona, como alguien que, además de su cuerpo y de las dificultades por las que este atraviesa, posee también un mundo interior igualmente pleno de dificultades (o de tesoros por descubrir). Dicha humanización requiere abandonar todo temor a que las emociones puedan entorpecer nuestra labor, por el contrario, exige el convencimiento de que una relación plenamente humana requiere el fluir de las emociones de una orilla a otra de la relación, exige asociar y nunca disociar las palabras de los afectos que las acompañan y exige, sobre todo, no disociar nunca a los demás separando su aspecto objetivo (al que te- 
nemos acceso con nuestros sentidos y con toda la tecnología que permite acrecentar nuestro poder de observación), de su mundo interior (al que sólo tenemos acceso con nuestro propio mundo interior, único instrumento capaz de llegar a, e intervenir en, el mundo interior del paciente), sólo porque ese mundo interior está plagado a veces de sombras siniestras.

Eric Cassell, especialista en Medicina Interna, miembro del Institute of Medicine de la National Academy of Sciences, Master del American College of Physicians, antiguo miembro de la President's National Bioethics Advisory Commission, afirmó hace ya 24 años, en la primera edición de The Nature of Suffering and the Goals of Medicine que los presupuestos en los que se fundamenta la medicina contemporánea no aportan ninguna base para la comprensión del sufrimiento y que, si bien para el dolor, para la dificultad respiratoria o para otras aflicciones del cuerpo la respuesta de la medicina contemporánea a la solicitud de alivio ha sido un rotundo sí, para el sufrimiento como un todo la respuesta no ha sido tan contundente. La razón de esta disparidad, dice Cassell, es que el sufrimiento inevitablemente involucra personas, mientras que la medicina actual está orientada con demasiada vehemencia sólo a los cuerpos y, bien mirado, los cuerpos no sufren, son las personas las que sufren (30).

En la segunda edición de su libro, hace 10 años, Casell mantuvo sin vacilación esta afirmación a pesar de que, sin lugar a dudas, la situación parece estar cambiando. Cada vez más, los médicos tomamos conciencia de que un ser humano que sufre requiere para su alivio, además de los conocimientos teóricos y de las técnicas y dispositivos tecnológicos necesarios para enfrentar la enfermedad, a otro ser humano a su lado pertrechado con esos conocimientos y esas técnicas y convencido de que, en la lucha contra el sufrimiento, el trato humano, persona a persona, sin temor a las emociones que se ponen en marcha de lado y lado, aunque no suficiente, sí es indispensable en la búsqueda del anhelado alivio. Recordando a Cassell, "uno no puede evitar 'verse involucrado' con el paciente y al mismo tiempo enfrentar de manera eficaz el sufrimiento" (31).

\section{Referencias}

1. Putnam, Hilary. The meaning of "Meaning". En: Mind, language and Reality. Cambridge: Cambridge University Press; 1975: p 229.

2. Wittgenstein,Ludwig. Investigaciones Filosóficas. Barcelona: Ediciones Altaya; 1999: p 18.

3. Freud, Sigmund. Lo inconsciente. Obras Completas de Sigmund Freud. Tomo II. Madrid: Biblioteca Nueva; p. 2069.
4. Platón. Político. En: Diálogos V: Parménides, Teeteto, Sofista, Político. 261d Santacruz, Maria Isabel (Traductora). Madrid: Editorial Gredos; 1988: p 509.

5. Platón. Político. En: Diálogos V: Parménides, Teeteto, Sofista, Político. 264a267b. Santacruz, Maria Isabel (Traductora). Madrid: Editorial Gredos; 1988: pp 514-522.

6. Laertius, Diogenes. Lives of Eminent Philosophers. 6, 2, 40. Hicks D (Traductor) Volumen II. London: William Heinemann; 1925: p 43.

7. Steinman, Bárbara. ¿Qué es definir en el Político de Platón?. Revista latinoamericana de filosofía 2008; 31 (1): 63-91.

8. Juan 1: 1. Biblia de Jerusalén, Edición Española. Bilbao: Desclée de Brouwer 1975: p 1505

9. Juan 1: 1. Sagrada Biblia. Reina-Valera: p 1793. Disponible en http://www.ccel org/ccel/bible/esrv.pdf. Consultado el 3 de mayo de 2014.

10. Sebastián-Yarza, Florencio. Diccionario Griego-Español. Tomo II. Barcelona: Editorial Ramón Sopena; 1999: p 849.

11. Aristotle. The Art of Rhetoric. 1355b. Freese, John Henry (Traductor). London: William Heynemann; 1926: p 13.

12. Aristotle. The Art of Rhetoric. 1378a. Freese, John Henry (Traductor). London William Heynemann; 1926: p 173.

13. Aristotle. The Art of Rhetoric. 1356b. Freese, John Henry (Traductor). London William Heynemann; 1926: pp 19-23.

14. Aristóteles. Acerca del Alma. 413a 1-4. Calvo-Martínez, Tomás (Traductor) Barcelona: Editorial Gredos; 1998: p 86.

15. Aristóteles. Acerca del Alma. 414a 29-34, 414b 1-419. Calvo-Martínez, Tomás (Traductor). Barcelona: Editorial Gredos; 1998: pp 91-92.

16. Aristóteles. Acerca del Alma. 429a 16-24, 429b 9. Calvo-Martínez, Tomás (Traductor). Barcelona: Editorial Gredos; 1998: pp 146-147.

17. Aristóteles. Ética a Nicómaco. 1095a. Araújo M, Marías J (Traductores). Octava Edición. Madrid: Centro de Estudios Políticos e Institucionales; 2002: pp 2-3.

18. Aristóteles. Ética a Nicómaco. 1097b. Araújo M, Marías J (Traductores). Octava Edición. Madrid: Centro de Estudios Políticos e Institucionales; 2002: pp 7-8.

19. Rahe, Paul Anthony. Republics Ancient \& Modern, Vol. 1: The Ancien Régime in Classical Greece. Chapel Hill: The University of North Carolina Press; 1994 p 21.

20. Aristóteles. Política. 1253a 1-4. Gómez-Robledo, Antonio (Traductor). Segunda Edición. México: Universidad Nacional Autónoma de México; 2000: pp 3-4.

21. Aristóteles. Política. 1253a 28-29. Gómez-Robledo, Antonio (Traductor). Segunda Edición. México: Universidad Nacional Autónoma de México; 2000: pp 4-5.

22. Coetzee, John Maxwell. Diario de un mal año. Barcelona: Random House Mondadori; 2007: p. 151.

23. Freudenberger, HJ. Staff burn-out. Journal of Social Issues 1974; 30 (1): 159165.

24. Institute for Quality and Efficiency in Health Care. What is burnout syndrome? Disponible en http://www.ncbi.nlm.nih.gov/pubmedhealth/PMH0050545/. Consultado el 4 de mayo de 2014.

25. Strawson, Peter Frederick. Individuals. London: Routledge; 1971: pp 87-116.

26. Strawson, Peter Frederick. Freedom and Resentment. En: Freedom and Resentment and other essays. London: Routledge; 2008: pp 1-28.

27. Alasdair MacIntyre. Animales racionales y Dependientes. Barcelona: Editorial Paidós; 2001: 15-33.

28. Kahr, Brett. Donald Woods Winnicott, retrato y biografía. Madrid: Biblioteca Nueva; 1999: p 155.

29. Winnicott, Donald Woods. Anxiety associated with Insecurity (1952). En Through Paediatrics to Psychoanalysis: Collected Papers. London: Rouletdge; 2014: $97-100$

30. Cassell, Eric. The Nature of Suffering and the Goals of Medicine. Second Edition Oxford: Oxford University Press; 2004: p V.

31. Cassell, Eric. The Nature of Suffering and the Goals of Medicine. Second Edition. Oxford: Oxford University Press; 2004: p 290. 